\title{
Special issue on simulation, optimization and identification
}

\author{
José Luis Zapico Valle • \\ María Placeres González Martínez
}

Published online: 5 October 2010

(C) Springer Science+Business Media B.V. 2010

This special issue is related to the Second International Conference on Multidisciplinary Design Optimization and Applications, which took place at the Engineering Polytechnic School (EPSI), Gijón, Spain on the 2-5 September 2008. This conference was organized by the Association for Simulation and Multidisciplinary Design Optimization (ASMDO). The association was founded in June 2005 to promote activities related to simulation, modelling and optimization. It is led by Prof. David Bassir and seeks international collaborations between researchers and engineers in the aforementioned fields. This ASMDO's conference is a natural continuation of the previous successful ones that took place in Belfort (2006), and Besançon (2007), France. The special issue includes nine papers, which were carefully selected on the basis of the evaluations and comments by the conference session chairs and additionally they undergone a thorough peer-review procedure.

Design optimization deals with the optimal design of structural elements or systems. Nowadays, there is a growing interest on structural optimiza-

J.L. Zapico Valle ( $\varangle)$ · M.P. González Martínez Universidad de Oviedo, Campus de Gijón 7.1.16, 33203 Gijón, Spain e-mail: jzapico@uniovi.es

M.P. González Martínez e-mail:placeres@uniovi.es tion in automotive, aeronautical, mechanical, civil, nuclear, naval and off-shore engineering, to name only a few, due to the increase of technological competition. Simulation is quite close to the optimization in the sense that both are used in the design stage and are based on the same software models. Parameter identification is usually posed as an optimization issue, in which a defined error function is minimized. Thus, the same numerical techniques are used in both applications. The main scientific challenges of design optimization are concerned with the development of strong and efficient numerical techniques and with the computational organization required for the necessary coupling of software systems. The application to real problems in these fields, however, appears to be very difficult due to the gap existing between the industrial requirements and the university research. This special issue includes articles on simulation, optimization and identification, all of them having related numerical approaches and trying to bring closer the academia and the industry activities.

We should like to thank all the people that contributed to the success of the conference and this special issue. Particularly, we want to thank the authors for accepting our invitation and taking the effort to extend and revise their papers for this issue. We also ap- 
preciate the reviewers for their invaluable comments and feedback that contributed to enhance the papers. Finally, we are grateful to all the sponsors whose support made the conference possible. We would like to extend our acknowledgement to the Editor-in-Chief of
Meccanica, Prof. Vincenzo Parenti Castelli, and the editorial staff for giving us the opportunity to compile this special issue, and Dr. Nathalie Jacobs, Springer Publishing Editor, for her collaboration on publishing it. 